\title{
O VISÍVEL E O INVISÍVEL NOS CADERNOS ESCOLARES DE UMA ALUNA DA TERCEIRA IDADE NA EJA
}

Alboni Marisa Dudeque Pianovski Vieira Eliane Küster $\left.{ }^{*}\right)$

\section{INTRODUÇÃO}

Este artigo trata dos cadernos escolares como fontes documentais, no âmbito da história cultural (CHARTIER, 1990). É sabido que os cadernos escolares constituem "relevante artefato material da escola contemporânea, cujo estudo se mostra uma excelente fonte de pesquisa" (OLIVEIRA, 2008, p. 129). Nesse sentido, destaca Grinspun (2008) que "cada caderno tem o jeito de cada um de nós, de suas preferências e da forma como se tratavam essas preferências", acrescentando que "cada um colocava no seu [caderno], além do que era solicitado, copiado, criado, uma maneira peculiar de traduzir o existente" (GRINSPUN, 2008, p. 261).

Nem tudo, porém, fica registrado nos cadernos. Viñao-Frago (2008) afirma que os cadernos "silenciam, não dizem nada sobre as intervenções orais ou gestuais do professor e dos alunos, sobre seu peso e o modo como ocorrem e se manifestam, sobre o ambiente ou clima da sala de aula" (VIÑAO-FRAGO, 2008, p. 25). Ir em busca dessas intervenções e do ambiente em que ocorreram justifica a realização deste estudo sobre os cadernos escolares. Como observa Oliveira (2008), nessa seara, os sujeitos da escola são também considerados:

No caso dos cadernos escolares, os sujeitos a serem conhecidos pelo estudo são, prioritariamente, os alunos a quem eles pertenciam, mas não só. O estudo deixa entrever alguns dos demais sujeitos da escola - como professores, suas práticas e, portanto, suas afiliações pedagógicas -, os conteúdos escolares e a metodologia em ação, as adesões epistemológicas e metodológicas da instituição e mesmo as regras gerais da política educacional atual. (OLIVEIRA, 2008, p. 130)

\footnotetext{
${ }^{(*)}$ Alboni Marisa D.P. Vieira. Doutora em Educação. Professora do Programa de Pós-Graduação em Educação (Mestrado e Doutorado) da PUCPR. Professora dos cursos de Pedagogia e de História da PUC-PR. E-mail: alboni@alboni.com.

Eliane Küster. Licenciada em Pedagogia, especialização em Psicopedagogia e em Educação Especial. Mestranda em Educação pela Pontifícia Universidade Católica do Paraná (PUC-PR). Diretora do CMEI Professora Ivone Nester Ravaglio da Prefeitura Municipal de São José dos Pinhais (PR). E-mail: likuster@yahoo.com.br.
} 
O objetivo geral do estudo foi, desta forma, investigar o que os cadernos escolares de uma aluna da terceira idade apresentaram no contexto das práticas e pautas escolares, sociais e culturais, à época em que ela frequentou uma classe de EJA - Educação de Jovens e Adultos, em uma escola da Rede Municipal de Ensino de Curitiba, no período de 2003 a 2004. Como objetivos específicos, estabeleceu-se: considerar os cadernos escolares como fontes de pesquisa; apresentar a EJA como uma oportunidade de aprendizagem; e verificar nos cadernos escolares de uma aluna da EJA, seus diferentes usos e seus possíveis significados.

O estudo possibilitou que fossem "acionadas estratégias múltiplas de pesquisa" (RIBEIRO, 2003, p. 287), entre elas, a pesquisa bibliográfica, a pesquisa documental e a pesquisa de campo.

O aporte teórico do trabalho está relacionado à história cultural (CHARTIER, 1990) sendo que os autores fundantes da pesquisa foram: Oliveira (2008), Grinspun (2008), Viñao-Frago (2008), Razzini (2008) e Julia (2001), entre outros.

Para a realização da pesquisa documental foram utilizadas fontes impressas, especificamente dois cadernos escolares, materiais que, segundo Gil (2010, p. 31), também são capazes de "comprovar algum fato ou acontecimento", considerados como fontes documentais.

Além da pesquisa bibliográfica e da pesquisa documental, foi utilizada a pesquisa de campo, com apoio nos procedimentos da história oral, metodologia que "pode ser empregada em pesquisas sobre temas recentes, ao alcance da memória dos entrevistados, envolvendo acontecimentos ocorridos num espaço de aproximadamente 50 anos", como bem explica Vieira (2015, p. 372).

A história oral, segundo Alberti (2014), “consiste na realização de entrevistas [...] com indivíduos que participaram de, ou testemunharam, acontecimentos e conjunturas do passado e do presente", fato que permite "o acesso a 'histórias dentro da História' ampliando as possibilidades de interpretação do passado" (ALBERTI, 2014, p. 155).

Constantino (2004) esclarece que além de "captar bem mais do que alguns dados", por meio da história oral é possível “captar a experiência dos narradores, suas tradições, mitos, porventura narrativas de ficção que se encontravam no fundo da memória, assim como as crenças existentes no seu grupo" (CONSTANTINO, 2004, p. 63-64).

O estudo foi dividido em três capítulos: no início, traz-se os cadernos escolares como fontes de pesquisa para a História da Educação; em seguida, descreve-se a EJA como uma oportunidade de aprendizagem para aqueles que não concluíram seus estudos na idade regular; e, ao 
final, apresenta-se uma análise sobre os registros de uma aluna da terceira idade que frequentou a EJA.

\section{CADERNOS ESCOLARES: FONTES DE PESQUISA PARA A HISTÓRIA DA EDUCAÇÃO}

Os cadernos escolares, assim como outros materiais, passaram a ser reconhecidos como fontes documentais significativas, a partir do advento da história cultural (CHARTIER, 1990). Reconhece Grinspun (2008) que "há uma inesgotável fonte de conhecimentos proporcionada por uma pesquisa dos cadernos escolares" (GRINSPUN, 2008, p. 259).

De acordo com Viñao-Frago (2008), os estudos realizados quanto ao enfoque, tema e usos dos cadernos escolares demonstraram que eles foram utilizados como: fonte para o conhecimento das imagens e representações sociais, instrumentos de aculturação escrita, veículos transmissores de valores e atitudes, modo de doutrinação ideológica e política, meio para o estudo do currículo e das diferentes disciplinas e atividades escolares, inovação educativa dentro do movimento da Escola Nova e instrumento de expressão pessoal e subjetiva do alunos.

Viñao-Frago (2008, p. 18) ainda destaca que, a partir do momento em que os cadernos escolares passaram a ser considerados como fontes históricas, surgiu também o interesse pelo "estudo de seus aspectos materiais (formato, dimensões, disposição dos espaços gráficos etc.), de sua iconografia (interior e capas, impressas ou realizadas pelo aluno) e de seus diferentes usos", com o objetivo de "elaborar uma tipologia que ordene e classifique os vários tipos de cadernos", bem como de perceber as possibilidades e os limites que esse estudo permite.

O estudo dos cadernos escolares pode contribuir para a contextualização de práticas escolares, "aqui entendidas como parte do que se tem definido historicamente na última década como cultura escolar" (RAZZINI, 2008, p. 92), que, segundo Julia (2001), é "um conjunto de normas que definem conhecimentos a ensinar e condutas a inculcar e um conjunto de práticas que permitem a transmissão desses conhecimentos e a incorporação desses conhecimentos” (JULIA, 2001, p. 10).

Frente a esse entendimento, Viñao-Frago (2008) considera o caderno como um produto da cultura escolar, explicando que:

Quer se contemple desde a história da infância, da cultura escrita ou da educação, nunca se deve perder de vista que, em última análise, o caderno é um produto da cultura escolar, de uma forma determinada de organizar o trabalho em sala de aula, de 
ensinar e aprender, de introduzir os alunos no mundo dos saberes acadêmicos e dos ritmos, regras e pautas escolares.

Como produto escolar, o caderno reflete a cultura própria do nível, etapa ou ciclo de ensino em que é utilizado (VIÑAO-FRAGO, 2008, p. 22).

Grinspun (2008) explica que “o caderno envolve questões visíveis e invisíveis, ideias e conteúdos que superam o que vemos e tocamos", ou seja, os cadernos escolares têm significados que vão além do que está escrito neles, "permitem refletir sobre os processos de aprendizagem, o currículo, as memórias, as histórias de vida, os registros de conteúdos ensinados e avaliados e a comunicação entre pais e responsáveis” (GRINSPUN, 2008, p. 264). Desta forma, os estudos sobre os cadernos escolares "possibilitam examinar percursos escolares, registros de aprendizagem, correções e até mesmo o interesse do aluno com a aprendizagem vivida" (GRINSPUN, 2008, p. 259).

Ainda conforme Viñao-Frago (2008), “os cadernos escolares devem ser situados como fonte histórica no contexto das práticas e pautas escolares, sociais e culturais de sua época, seu uso há de completar-se e combinar-se com outras fontes históricas" (VIÑAO-FRAGO, 2008, p. 27). Nesse sentido, Grinspun (2008) acrescenta que a riqueza do caderno "transcende o processo de ensinoaprendizagem para inserir-se tanto na formação do professor/educador quanto nas expectativas e interesses dos alunos" (GRINSPUN, 2008, p. 259).

Para Grinspun (2008, p. 259 e 260), os cadernos guardados registram também a memória de uma época, guardam histórias incríveis de um passado que não voltará jamais e permitem identificar um pouco os passos da vida cotidiana de então, nos diferentes períodos, enfatizando que:

Se pensarmos que o caderno é a história viva de uma determinada escolaridade, de uma determinada escola/professora e se estivermos interessados em perceber como essa formação ocorre, estaremos diante de uma nova lição de vida. Basta observar o que as folhas dizem ou não, as folhas brancas encontradas em algumas páginas, os silêncios retidos que nunca uma escrita será capaz de traduzir (GRINSPUN, 2008, p. 263).

Diante da inesgotável fonte de conhecimentos que a pesquisa sobre os cadernos escolares proporciona, Grinspun (2008) afirma: “Quanto mais mergulho neles, mais descubro sobre quem ensinou e quem aprendeu" (GRINSPUN, 2008, p. 259). Esta afirmação é corroborada por ViñaoFrago (2008), quando se refere ao fato de que não existe objeto, fenômeno, acontecimento ou assunto que, considerado de perspectivas diferentes, não mostre aspectos antes não apreciados. 
“Tudo depende, pois, da posição que adota aquele que olha. O lugar de onde se olha condiciona não somente o que se vê, mas também como se vê o que se vê” (VIÑAO-FRAGO, 2008, p. 15).

Por tais razões, este estudo sobre cadernos escolares, enquanto fontes históricas no contexto das práticas docentes e discentes, bem como, no contexto das pautas escolares, sociais e culturais, foi realizado em conjunto com outras fontes históricas, contemplando inclusive informações procedentes da história oral.

\section{EJA: UMA OPORTUNIDADE PARA A APRENDIZAGEM}

Com a promulgação da Lei de Diretrizes e Bases da Educação Nacional, Lei n. ${ }^{\circ}$ 9.394/96, a EJA - Educação de Jovens e Adultos passou a ser considerada uma modalidade da Educação Básica com especificidade própria, "destinada àqueles que não tiveram acesso ou continuidade de estudos no ensino fundamental e médio na idade própria" (BRASIL, 1996, p. 18). Em seu artigo 37, $\S 1^{\circ}$, a Lei 9.394/96 estabelece que:

$\S 1^{\circ}$. Os sistemas de ensino assegurarão gratuitamente aos jovens e aos adultos, que não puderam efetuar os estudos na idade regular, oportunidades educacionais apropriadas, consideradas as características do alunado, seus interesses, condições de vida e de trabalho, mediante cursos e exames (BRASIL, 1996, p. 18).

Em consequência dessas determinações legais, em 10 de maio de 2000, foram promulgadas as Diretrizes Curriculares Nacionais para a Educação de Jovens e Adultos, elaboradas pelo Conselho Nacional de Educação, e em 9 de janeiro de 2001, o Governo Federal incluiu a EJA no Plano Nacional de Educação (BRASIL, 2001).

Essa modalidade de ensino é caracterizada pela diversidade do perfil dos seus educandos (adolescentes, jovens, adultos e idosos), “com relação à idade, o nível de escolarização em que se encontram, à situação socioeconômica e cultural, às ocupações e a motivação pela qual procuram a escola" (PARANÁ, 2006, p. 27).

Compreender o perfil do educando da EJA requer:

[...] conhecer a sua história, cultura e costumes, entendendo-o como um sujeito com diferentes experiências de vida e que em algum momento afastou-se da escola devido a fatores sociais, econômicos, políticos e/ou culturais. Entre esses fatores, destacamse: o ingresso prematuro no mundo do trabalho, a evasão ou a repetência escolar (PARANÁ, 2006, p. 29). 
A EJA, portanto, “deve contemplar ações pedagógicas específicas que levem em consideração o perfil do educando jovem, adulto e idoso que não obteve escolarização ou não deu continuidade aos seus estudos por fatores, muitas vezes, alheios à sua vontade" (PARANÁ, 2006, p. $30)$.

Sendo assim, uma das demandas que merecem atenção especial no processo educativo da EJA é a de pessoas idosas, que apresentam uma temporalidade específica no processo de aprendizagem: "buscam a escola para desenvolver ou ampliar seus conhecimentos, bem como têm interesse em outras oportunidades de convivência social e realização pessoal" (PARANÁ, 2006, p. $30)$.

Os adolescentes, jovens, adultos e idosos que procuram a EJA trazem consigo uma bagagem de conhecimentos de outras instâncias sociais, "experiências de vida que são significativas e devem ser consideradas na elaboração do currículo escolar, o qual tem uma metodologia diferenciada porque apresenta características distintas do ensino regular" (PARANÁ, 2006, p. 30).

De acordo com as Diretrizes Curriculares da Educação de Jovens e Adultos do Estado do Paraná (2006), a EJA, enquanto modalidade educacional, tem como finalidades e objetivos “o compromisso com a formação humana e com o acesso à cultural geral, de modo que os educandos aprimorem sua consciência crítica, e adotem atitudes éticas e compromisso político, para o desenvolvimento da sua autonomia intelectual” (PARANÁ, 2006, p. 27).

A EJA tem a responsabilidade de fornecer subsídios para que seus alunos se tornem sujeitos ativos, críticos, criativos e democráticos, com um universo que contempla diferentes culturas, saberes e especificidades a serem priorizados. Possui, também, papel fundamental na socialização dos sujeitos, "agregando elementos e valores que os levem à emancipação e à afirmação de sua identidade cultural" (PARANÁ, 2006, p. 29).

Segundo as Diretrizes Curriculares da Educação de Jovens e Adultos do Estado do Paraná (2006):

A EJA deve ter uma estrutura flexível e ser capaz de contemplar inovações que tenham conteúdos significativos. Nesta perspectiva, há um tempo diferenciado de aprendizagem e não um tempo único para todos. Os limites e possibilidades de cada educando devem ser respeitados; portanto, é desafio [...] apresentar propostas viáveis para que o acesso, a permanência e o sucesso do educando nos estudos estejam assegurados (PARANÁ, 2006, p. 28).

É necessário proporcionar o envolvimento dos alunos da EJA nas práticas escolares, com acesso aos saberes em suas diferentes linguagens. "Tais práticas devem estar intimamente 
articuladas às suas necessidades, expectativas e trajetórias de vida, e devem servir como incentivo para que continuem os estudos", para que, dessa forma, eles se tornem sujeitos na construção do conhecimento "mediante a compreensão dos processos de trabalho, de criação, de produção e de cultura" (PARANÁ, 2006, p. 28).

As Diretrizes Curriculares (2006) também enfatizam questões relativas aos educandos que frequentam a EJA e as relações com o tempo, os conteúdos, perspectivas e projetos de vida:

O tempo que um educando participa da EJA tem valor próprio e significativo e, portanto, a escola deve superar o ensino de caráter enciclopédico, centrado mais na quantidade de informações do que na relação qualitativa com o conhecimento. Quanto aos conteúdos específicos de cada disciplina, deverão estar articulados à realidade, considerando sua dimensão sócio-histórica, articulada ao mundo do trabalho, à ciência, às novas tecnologias, dentre outros.

Com relação às perspectivas dos educandos e seus projetos de vida, a EJA poderá colaborar para que eles ampliem seus conhecimentos de forma crítica, viabilizando a reflexão pela busca dos direitos de melhoria de sua qualidade de vida (PARANÁ, 2006, p. 29).

Cada aluno que procura a EJA “apresenta um tempo social e um tempo escolar vivido, o que implica a necessidade de reorganização curricular, dos tempos e dos espaços escolares, para a busca de sua emancipação", e [...] "pode-se dizer que os educandos viveram e vivem tempos individuais e coletivos, os quais compreendem os momentos da infância, da juventude, da vida adulta, no contexto das múltiplas relações sociais". Cabe ainda destacar que "a organização dos tempos e dos espaços escolares interfere na formação dos educandos, seja para conformar ou para produzir outras práticas de significação" (PARANÁ, 2006, p. 33).

Muitos alunos, ao ingressarem na EJA, trazem modelos internalizados de vivências escolares ou outras. "Neles predomina a ideia de uma escola tradicional, onde o educador exerce o papel de detentor do conhecimento e o educando de receptor passivo desse conhecimento", por isso "muitos supõem que seja da escola a responsabilidade pela sua aprendizagem" (PARANÁ, 2006, p. $30)$.

Destaca-se o papel do educador da EJA, durante o processo educativo, estimulando a autonomia intelectual dos alunos para que eles continuem seus estudos. "Cabe ao educador incentivar a busca constante pelo conhecimento produzido pela humanidade, presente em outras fontes de estudo ou pesquisa", bem como estimular o estudo individual, necessário, "quando se trata 
da administração do tempo de permanência desse educando na escola e importante na construção da autonomia" (PARANÁ, 2006, p. 29).

Segundo as Diretrizes Curriculares (2006), deve-se construir essa autonomia intelectual, a fim de que os educandos se tornem sujeitos ativos do processo educacional:

A emancipação humana será decorrência da construção dessa autonomia obtida pela educação escolar. O exercício de uma cidadania democrática pelos educandos da EJA será o reflexo de um processo cognitivo, crítico e emancipatório, com base em valores como respeito mútuo, solidariedade e justiça (PARANÁ, 2006, p. 29).

O desafio de desenvolver processos de formação humana, articulados a contextos sóciohistóricos, a fim de que se reverta a exclusão e se garanta aos educandos o acesso, a permanência e o sucesso no início ou no retorno desses sujeitos à escolarização básica, desta forma, está na base do trabalho pedagógico da EJA.

\section{CADERNOS ESCOLARES: OS REGISTROS DE UMA ALUNA NA EJA}

Esquecidos há algum tempo, estavam dois cadernos escolares que pertenceram a uma senhora da terceira idade e que foram utilizados durante os anos de 2003 e 2004, período em que ela frequentou uma classe de EJA, em uma escola de Rede Municipal de Ensino de Curitiba/PR. Esses materiais escolares, ou melhor, essas fontes históricas foram encontradas ao final do ano de 2016, no fundo de uma antiga estante de madeira, em meio a outros documentos.

Ao encontrar esses cadernos escolares, meio que por acaso, durante uma reforma do imóvel onde essa senhora reside, surgiu o desejo de continuar preservando-os, a princípio apenas com a intenção de cuidar do bem material, sem a pretensão de que um dia eles pudessem ser úteis por algum o motivo, bem como pelo significado que tiveram, pelo valor sentimental e pelas lembranças que traziam e representavam para ela, que hoje é ainda uma mulher independente e batalhadora, uma dona de casa ativa, com setenta e cinco anos de idade, cheia de vida e que luta a cada dia para alcançar seus objetivos.

Após observar por algumas vezes esses materiais, foi possível perceber a riqueza de dados históricos que uma análise mais detalhada sobre eles poderia fornecer. Diante dessa situação, surgiu o interesse em desenvolver esta pesquisa, com o intuito de captar mais do que apenas alguns dados impressos, mas sim tentar captar o significado desses cadernos na história de vida dessa senhora. Para tanto, foi utilizada a metodologia da história oral, por meio de entrevistas com a própria autora dos cadernos, com os devidos cuidados éticos, desde o "convite e à cessão de direitos sobre o 
depoimento para uso dos dados na pesquisa" (VIEIRA, 2015, p. 372), transcrição e retorno dos dados à entrevistada.

No decorrer das entrevistas, a senhora relatou que teve uma infância muito humilde, sem condições de efetuar os seus estudos na idade regular. Desde muito jovem, ela já contribuía com o sustento da casa, auxiliando seus pais em lavouras e serrarias, no Município de Faxinal, no norte do Estado do Paraná, e que, portanto, não havia tido a oportunidade de frequentar a escola regularmente.

Durante algum tempo, por volta dos seus sete ou oito anos de idade, havia estudado em uma classe multisseriada, em uma escola rural localizada nas instalações de uma serraria. As condições para estudar naquela época, explicou, eram muito precárias, pois sua residência ficava em uma chácara distante da escola. Segundo a entrevistada, ela e sua irmã mais nova tinham que caminhar cerca de três quilômetros para chegar até a escola rural, sem calçados apropriados, mal agasalhadas, sem a companhia de seus responsáveis, sujeitas a todo tipo de perigos durante o percurso (ataques de animais, encontro com tropas de bois, intempéries, acidentes etc.). Algumas vezes, acrescentou, a fome e o desgaste físico proporcionado por aquela longa jornada também castigavam as duas meninas, então elas precisavam parar no caminho para descansar e se alimentar da merenda que preparavam em casa e armazenavam em marmitas improvisadas, que eram antigas latas de margarina.

Mesmo enfrentando tais dificuldades de acesso, a entrevistada lembrou com carinho dessa época, relatando que gostava muito de estudar e que ficava orgulhosa quando sua professora solicitava a ela para que auxiliasse os colegas na execução das atividades ou que tomasse conta da sala de aula.

Apesar do esforço para frequentar a escola, mesmo que por um curto período durante sua infância, a senhora não possuía um histórico escolar ou qualquer outro documento que comprovasse sua escolaridade, o que lamentava.

No ano de 2003, no entanto, algumas senhoras da terceira idade, moradoras do bairro Alto Boqueirão em Curitiba (PR), com histórias de vida semelhantes à da entrevistada, tomaram conhecimento de um curso de EJA que era ofertado em uma das escolas da Rede Municipal de Ensino. Resolveram, então, formar um grupo para retomar os estudos, convidando-a para se integrar a elas. Logo no início, narrou, havia ficado um pouco assustada, relutando em aceitar o convite, pois não acreditava ser capaz de voltar a frequentar uma escola. Depois de vários incentivos por parte de familiares e amigos, contudo, decidiu encarar o desafio. 
O curso era ministrado em uma escola próxima de sua residência. O grupo de senhoras se reunia todas as noites, das $19 \mathrm{~h}$ às $22 \mathrm{~h}$, e uma colega ia incentivando a outra. Elas frequentaram as aulas da EJA durante os anos de 2003 e 2004, com um objetivo em comum: a obtenção do tão sonhado histórico escolar referente a escolaridade de $1^{\mathrm{a}}$ a $4^{\mathrm{a}}$ série.

No decorrer da análise dos dois cadernos escolares utilizados pela entrevistada, foi possível refletir sobre a utilização desses materiais escolares como uma fonte para pesquisa, voltada ao estudo do cotidiano escolar e daquilo que nele existe de diferente do previsto e normatizado. Ao mergulhar em seus cadernos, foram descobertas marcas de sua singularidade, o que contribuiu para uma reflexão sobre o modo como ela expressou conhecimentos, sentimentos e incertezas. Foram observadas suas relações com elementos do trabalho pedagógico efetivo com os conteúdos escolares e atividades oficiais da escola, com os papéis sociais, entre outras coisas.

Esses dois cadernos escolares também foram analisados em seus aspectos físicos: são do tipo universitário, destinados para uma matéria, sem divisórias, com espiral, ambos têm o mesmo formato vertical, medindo 203 x $280 \mathrm{~cm}$, com 96 folhas cada um, com capas simples, ilustradas com imagens de jovens esportistas. O primeiro caderno apresenta capa de papelão fino, já o segundo caderno apresenta capa dura, feita com papelão mais encorpado. Segundo relato da entrevistada, eles foram adquiridos aleatoriamente, sem qualquer influência das características elencadas, simplesmente pelo fato de que os cadernos seriam itens básicos para que ela frequentasse as aulas. Nas capas dos cadernos, não havia nenhuma identificação com o nome da aluna ou sobre a turma à qual pertencia.

Foi possível perceber, nos registros, o uso rotineiro de caneta esferográfica, alternando entre as cores azul e preta, lápis e borracha. Observou-se o emprego de lápis de cor, giz de cera e canetas coloridas de maneira muito esporádica. O uso de caneta esferográfica vermelha era exclusivo da professora, durante correções individuais e para registrar alguns elogios nas conclusões dos exercícios, como por exemplo: "Parabéns! Muito bom!", o que leva a crer que essa prática provavelmente era apenas produto de regras estabelecidas na classe.

Com letra bem definida, seus registros quase não apresentaram rasuras, demonstrando terem sido realizados com atenção. Foi possível perceber a preocupação da aluna em não cometer erros e em relação à organização, à limpeza, ao capricho, ao aproveitamento dos espaços e à disciplina na utilização dos materiais, provavelmente seguindo padrões estéticos que lhe haviam sido impostos em outros tempos. Todas as anotações registradas pela entrevistada em seus cadernos eram dedicadas exclusivamente ao que dizia respeito aos conteúdos trabalhados em sala de aula. 
A aluna demonstrou seriedade nos estudos e preocupação em fazer tudo o que era solicitado. Textos, atividades, enunciados e exercícios foram registrados de maneira completa, feitos e corrigidos, quase sem enfeites ou outros detalhes, sempre de forma legível, com clareza e organização.

Percebe-se a presença marcante da interdisciplinaridade no desenvolvimento das aulas. Os conteúdos foram ministrados dentro de projetos de trabalho. A partir de temas como: Bolo do coração; A história do dinheiro; Papirus; Folclore; Fontes históricas; O trabalho no Brasil; Conhecendo a história do café; Construindo um ambiente saudável; O Natal, seu significado e seus símbolos; entre outros, a professora apresentava os projetos articulando-os aos conteúdos das disciplinas de Português, Matemática, História, Geografia, Ciências e Arte, partindo de informações significativas para seus alunos, que faziam sentido e tinham relação com suas experiências de vida.

Durante o desenvolvimento do projeto "Bolo do coração", por exemplo, nota-se que a professora apresentou a proposta de trabalho partindo da afetividade e aproveitando os vínculos de amizade presentes naquele grupo para estimular principalmente a produção e a interpretação de textos, mas também trabalhando pesquisa e análise de outras receitas de bolos, acentuação, frações, sistema de medidas, situações-problema, alimentação saudável, modos de produção etc.

Com o projeto "A história do dinheiro", a professora trouxe à baila conteúdos como: medidas de valor, sistema monetário, moeda brasileira, números decimais, ordem crescente e decrescente, escrita de números por extenso, produção e interpretação de textos, situações problemas envolvendo adição, subtração, multiplicação e divisão, frações, preços e mercadorias, fazendo relação entre os tipos de moedas que haviam servido como padrão monetário no Brasil e com quais delas os alunos daquela turma haviam convivido.

No projeto "O trabalho no Brasil", a professora apresentou os tipos ou formas de trabalho: escravo, servil e assalariado, trazendo também ao debate questões a respeito de trabalho indígena, trabalho dos imigrantes, trabalho da mulher, trabalho infantil, remuneração, carga horária dos trabalhadores, mudanças significativas nas relações de trabalho no Brasil, leis trabalhistas, direitos e deveres dos trabalhadores, organizações dos trabalhadores rurais, relação entre o nível de escolaridade e o mercado de trabalho, utilizando para isso situações-problema, desenho, pintura, legendas, produção e interpretação de textos, interpretação e elaboração de gráficos, porcentagem etc. As fotos abaixo são exemplos que ilustram algumas das relações entre o projeto "O trabalho no Brasil" e as experiências de vida da entrevistada: 


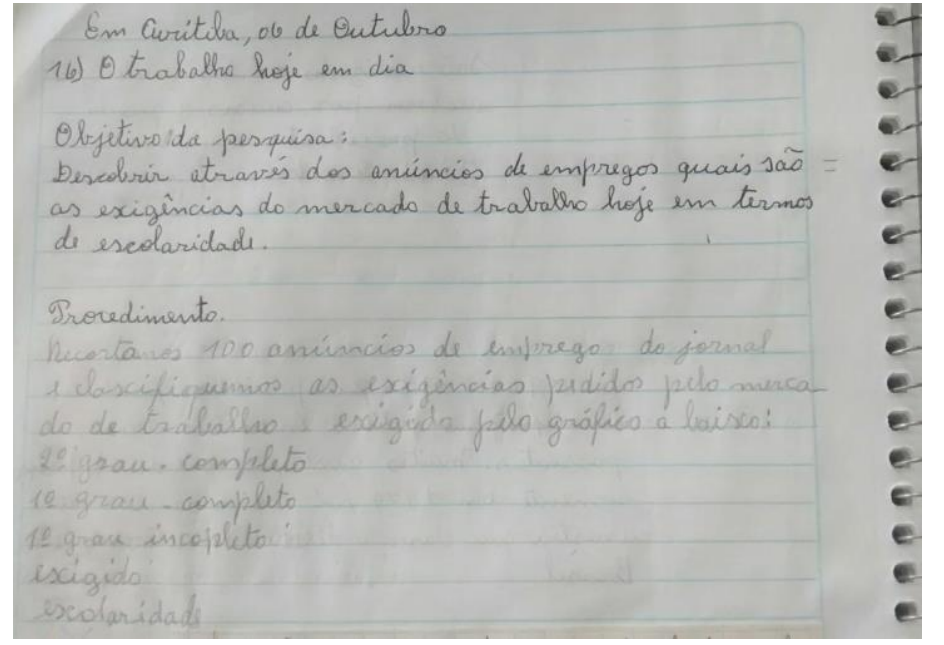

Figura 1: Enunciado da atividade proposta no projeto "O trabalho no Brasil", descreve o objetivo da pesquisa: "Descobrir através dos anúncios de empregos quais são as exigências do mercado de trabalho hoje, em termos de escolaridade" e o procedimento utilizado: "Recortamos 100 anúncios de emprego do jornal e classificamos as exigências pedidas pelo mercado de trabalho, exigido pelo gráfico abaixo: $2^{\circ}$ grau completo; $1^{\circ}$ grau completo; $1^{\circ}$ grau incompleto" (SILVA, 2003).

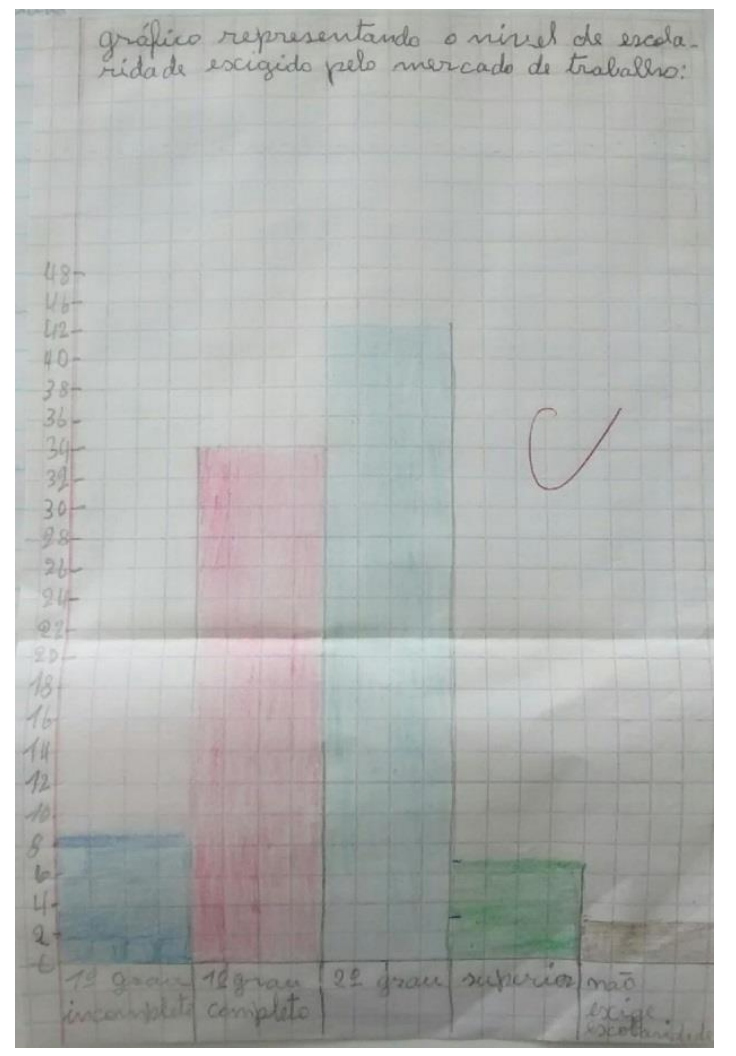

Figura 2: Gráfico representando o nível de escolaridade exigido pelo mercado de trabalho, legendas: azul escuro: $1^{\circ}$ grau incompleto; vermelho: $1^{\circ}$ grau completo; azul claro: $2^{\circ}$ grau; verde: superior; marrom: não exige escolaridade (Resultado da pesquisa do projeto "O trabalho no Brasil") (SILVA, 2003).

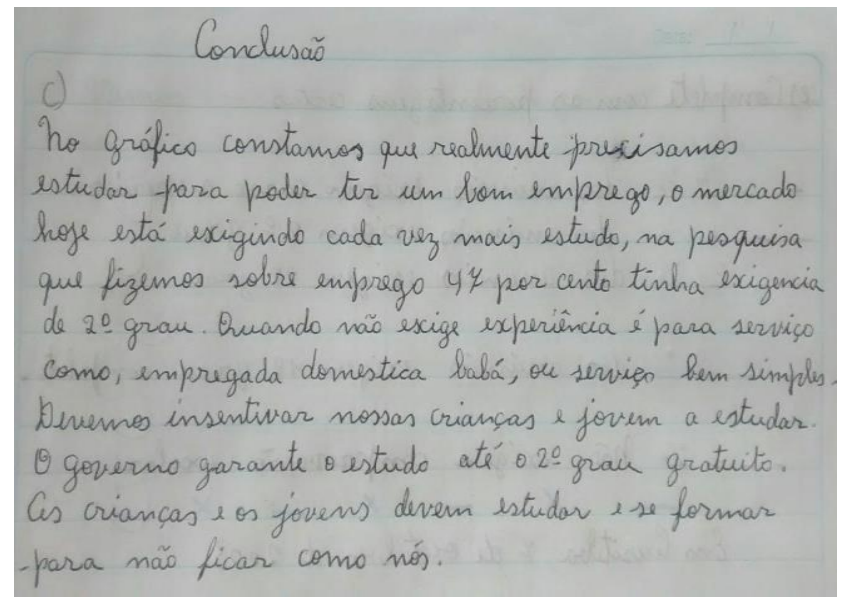

Figura 3: Produção de texto: Conclusão a respeito do gráfico sobre o nível de escolaridade exigido pelo mercado de trabalho (Resultado da pesquisa do projeto "O trabalho no Brasil") (SILVA, 2003). 
Em um dos cadernos analisados percebe-se um pouco sobre a forma como a professora estimulava os processos interativos entre os seus alunos, como as relações interpessoais se desenvolviam e como as interações ocorriam.

Foi possível perceber a dificuldade, ou talvez, a simples insegurança da aluna em produzir textos. Registros a respeito são mínimos e alguns dos personagens fictícios recebiam nomes de familiares ou colegas de sala de aula, quase sem ligação com o real.

Ficou evidenciado que metade de um dos cadernos estava destinada à "recuperação", especificamente separada para a disciplina de Matemática. A presença da tabuada ganhou lugar de destaque no verso da capa, as atividades e exercícios não estavam articulados aos projetos interdisciplinares, diversos exercícios foram registrados, executados e corrigidos de forma mais mecânica.

Também chamou atenção a presença de um vasto espaço com folhas em branco, resultado de um período em que a aluna não frequentara as aulas porque sua filha estava internada, com um grave problema de saúde.

Durante o estudo, portanto, foi possível conhecer com maior profundidade o comportamento escolar dessa aluna, sua relação com a escola e com os conteúdos. Também foi possível notar algumas de suas particularidades ao interagir com esses materiais como espaços próprios de expressão da sua individualidade e de alguns de seus critérios e valores.

\section{CONSIDERAÇÕES FINAIS}

Considerando a ampliação e a diversidade de fontes documentais, promovida pela história cultural, os cadernos escolares passaram a ser reconhecidos como tal, representando vasto campo para pesquisa em História da Educação. Nessa perspectiva, este estudo analisou questões visíveis e invisíveis, perceptíveis nos registros de cadernos escolares, evidenciando a possibilidade de utilização desses materiais como fontes históricas.

O contexto estudado foi o da EJA - Educação de Jovens e Adultos, modalidade de ensino considerada como outra oportunidade de aprendizagem para aqueles que não concluíram seus estudos na idade regular, caracterizada pela diversidade do perfil dos seus educandos (adolescentes, jovens, adultos e idosos), os quais trazem consigo uma bagagem de conhecimentos de outras instâncias sociais. É a EJA responsável por fornecer subsídios para que seus alunos se tornem 
sujeitos ativos, críticos, criativos e democráticos, contemplando diferentes culturas, saberes e especificidades que precisam ser priorizados na socialização dos sujeitos.

A partir da análise de dois cadernos utilizados por uma aluna que frequentou uma classe de EJA, em uma escola da Rede Municipal de Ensino de Curitiba/PR, durante o período de 2003 a 2004, foi possível contextualizar práticas escolares, refletindo-se sobre a utilização desses artefatos e sobre o que eles representam no cotidiano escolar, na relação entre o previsto e o normatizado. A pesquisa também trouxe à baila questões relacionadas aos conteúdos, aos sujeitos e às relações entre eles, percebidas ao mergulhar nas linhas e entrelinhas do material estudado.

Ao analisar esses cadernos, foi possível descobrir marcas de sua singularidade e sobre o modo como a aluna expressou conhecimentos, sentimentos e incertezas. Foram observadas suas relações com elementos do trabalho pedagógico efetivo, com os conteúdos escolares e as atividades oficiais da escola, bem como com os papéis sociais.

No desenvolvimento da pesquisa, surgiram indícios que puderam ser relacionados diretamente à realidade na qual a aluna estava inserida: informações sobre o cotidiano escolar, os sujeitos, as normas, o universo da escola, suas práticas e seus objetivos.

Em suma, o estudo sobre cadernos escolares permitiu aprofundar o conhecimento sobre os cadernos escolares, sua utilização e o que representam no cotidiano da escola, como espaços próprios de expressão da individualidade da aluna. 


\section{REFERÊNCIAS}

ALBERTI, Verena. Histórias dentro da História. In: PINSKY, Carla Bassanezi (Org.). Fontes históricas. São Paulo: Contexto, 2014, p. 155-202.

BRASIL. Lei 9.394, de 20 de dezembro de 1996. Estabelece as diretrizes e bases da educação nacional. Diário Oficial da União, Brasília, DF, 20/12/1996. Disponível em: http://www.planalto.gov.br/ccivil 03/leis/L9394.htm Acesso em: 20 jun. 2017.

BRASIL. Lei n ${ }^{\circ} 10.172$, de 9 de janeiro de 2001. Aprova o Plano Nacional de Educação e dá outras providências. Diário Oficial da União, Brasília, DF, 09/01/2001. Disponível em: http://portal.mec.gov.br/arquivos/pdf/L10172.pdf Acesso em: 20 jun. 2017.

CHARTIER, Roger. A história cultural. Entre práticas e representações. Trad. Maria Manuela Galhardo. Lisboa: Difel, 1990.

CONSTANTINO, Nuncia Santoro de. Teoria da História e reabilitação da oralidade: convergência de um processo. In: ABRAHÃO, M. H. M. B. (org.). A aventura (auto)biográfica: teoria e empiria. Porto Alegre: EDIPUCRS, 2004. p. 37-74.

GIL, Antônio Carlos. Como elaborar projetos de pesquisa. São Paulo: Atlas, 2010.

GRINSPUN, Mírian Paura Sabrosa Zippin. Velhos cadernos, novas emoções. In: MIGNOT, A. C. V. (org.). Cadernos à vista: escola, memória e cultura escrita. Rio de Janeiro: EdUERJ, 2008, p. 257-265.

JULIA, Dominique. A cultura escolar como objeto histórico. Revista Brasileira de História da Educação. Campinas, n. 1, jan./jun. 2001, p. 9-43. Disponível em: 〈http://rbhe.sbhe.org.br/index.php/rbhe/article/view/273/281> Acesso em: 12 abr. 2017.

OLIVEIRA, Inês Barbosa de. Aprendendo com os cadernos escolares: sujeitos, subjetividades e práticas sociais cotidianas da escola. In: MIGNOT, A. C. V. (org.). Cadernos à vista: escola, memória e cultura escrita. Rio de Janeiro: EdUERJ, 2008, p. 130-142.

PARANÁ. Secretaria de Estado da Educação. Diretrizes Curriculares da Educação de Jovens e Adultos. Secretaria de Estado da Educação. Curitiba: 2006. Disponível em: http://www.educadores.diaadia.pr.gov.br/arquivos/File/ diretrizes/dce_eja.pdf Acesso em: 21 jun. 2017.

RAZZINI, Marcia de Paula Gregorio. Instrumentos de escrita na escola elementar: tecnologias e práticas. In: MIGNOT, A. C. V. (org.). Cadernos à vista: escola, memória e cultura escrita. Rio de Janeiro: EdUERJ, 2008, p. 91-113.

RIBEIRO, José da Silva. Métodos e técnicas de investigação em Antropologia. Lisboa: Universidade Aberta, 2003.

SILVA, Izabel Afonso da. Caderno escolar da EJA. Curitiba: 2003.

VIEIRA, Alboni Marisa Dudeque Pianovski. A história cultural e as fontes de pesquisa. Revista HISTEDBR On-line. Campinas, $\mathrm{n}^{\circ}$ 61, p. 367-378, mar. 2015. Disponível em: https://periodicos.sbu.unicamp.br/ojs/index.php/histedbr/ article/view/8640533/8092. Acesso em: 08 mai. 2017.

VIÑAO-FRAGO, Antonio. Os cadernos escolares como fonte histórica: aspectos metodológicos e historiográficos. In: MIGNOT, A. C. V. (org.). Cadernos à vista: escola, memória e cultura escrita. Rio de Janeiro: EdUERJ, 2008, p. 1533. 


\section{RESUMO}

O artigo analisa os cadernos escolares de uma aluna da terceira idade no contexto das práticas e pautas escolares, sociais e culturais, em uma classe de EJA - Educação de Jovens e Adultos, na Rede Municipal de Ensino de Curitiba, no período de 2003 a 2004. Considerando os cadernos escolares como fontes de pesquisa e a EJA como oportunidade de aprendizagem, procurou-se identificar seus diferentes usos e possíveis significados. A pesquisa, de caráter bibliográfico, documental e de campo, apoiou-se nos estudos de Chartier (1990), Oliveira (2008), Grinspun (2008), Viñao-Frago (2008) e Julia (2001). Como resultado, foi possível refletir sobre os cadernos escolares, sua utilização e o que representam no cotidiano da escola, como espaços próprios de expressão da individualidade da aluna.

Palavras-chave: História da Educação, EJA - Educação de Jovens e Adultos, cadernos escolares.

\section{THE VISIBLE AND THE INVISIBLE IN THE SCHOOL NOTEBOOKS OF A SENIOR CITIZEN STUDENT IN EJA}

\section{ABSTRACT}

The article analyzes the classroom notebooks of a senior citizen student within the context of school, social and cultural practices and guidelines in an EJA (Youth and Adult Education) class in Curitiba's Municipal Education Network, from 2003 to 2004. Considering the notebooks as a source of research material and EJA as an opportunity for learning, the aim was to identify their different uses and possible meanings. The research, which was bibliographical, documentary and field-based, was grounded in studies by Chartier (1990), Oliveira (2008), Grinspun (2008), Viñao-Frago (2008) and Julia (2001). As a result, it was possible to reflect upon the notebooks, their use and significance in the school's day-to-day, as places where students could express their individuality.

Keywords: History of Education, EJA - Youth and Adult Education, classroom notebooks.

\section{LO VISIBLE Y LO INVISIBLE EN LOS CUADERNOS ESCOLARES DE UNA ALUMNA DE TERCERO EN LA EJA}

\section{RESUMEN}

Este artículo analiza los cuadernos escolares de una alumna de tercero, en el contexto de las prácticas y pautas escolares, sociales y culturales de una clase de la EJA, Educación de Jóvenes y Adultos, de la Red Municipal de Enseñanza de Curitiba, durante el periodo de 2003 a 2004. Valorando los cuadernos escolares como fuentes de investigación, y la EJA como una oportunidad de aprendizaje, se buscó identificar sus diferentes usos y posibles significados. La investigación, de carácter bibliográfico, documental y con trabajo de campo, se apoyó en los estudios de Chartier (1990), Oliveira (2008), Grinspun (2008), Viñao-Frago (2008) y Julia (2001). Como resultado, fue posible hacer una reflexión sobre los cuadernos escolares, su utilización y lo que representan, en el día a día de la escuela, como espacios propios de expresión de la individualidad de la alumna.

Palabras clave: Historia de la Educación, EJA - Educación de Jóvenes y Adultos, cuadernos escolares. 